\title{
2. Synthesis and Identification Methods for Zeolites and MOFs
}

\author{
L. Marcela Martínez T., ${ }^{1}$ Svetlana Ivanova, ${ }^{1}$ Benoît Louis, ${ }^{2}$ \\ José Antonio Odriozola
}

'Departamento de Química Inorgánica e Instituto de Ciencia de Materiales de Sevilla, Universidad de Sevilla - CSIC, Avda Américo Vespucio 49, 41092 Sevilla, Spain.

${ }^{2}$ CNRS Laboratoire de Synthèse, Réactivité Organiques et Catalyse (LaSyROC), UMR 7177, Université de Strasbourg (UDS), France.

Keywords: Synthesis, crystallization, X-ray diffraction, surface area measurement, electron microscopy

\section{Introduction}

Conceptually, there are no important differences between classical inorganic porous solids as zeolites and hybrid porous solids as metal-organic frameworks (MOFs) [1]. Based only on their porosity, both groups are porous solids with modular structure offering important structural diversity and, even more importantly, the possibility to synthesize them on-demand, with tailored properties for targeted applications. The difference between them lies in the units composing the structure, only inorganic for the case of zeolites, and of hybrid inorganic-organic nature for MOFs. Although MOFs are often considered hybrid materials mimicking zeolites, in the last decade they started to surpass the versatility of purely inorganic zeolites, also benefiting from permanent porosity. MOFs outstand by their large surface area and by the wide assortment of pore sizes and pore specific volumes that can be synthesized, both converting these materials in promising alternative to the zeolites even in their traditional fields of application such as gas separation and purification.

Both materials, by virtue of their structure (i.e. porosity, surface area, pore shape and functionalities), have found useful applications in almost all fields of human life where chemical, biochemical or physicochemical processes take place. They are used for the purification of gases or liquid mixtures by sorption, sieving, and filtering. More specifically, zeolites are 
used as ion exchangers (they have replaced polyphosphates as water softeners for laundry purposes), as catalysts in refining and petrochemistry or, more recently, for the synthesis of fine chemicals [2-5]. MOFs are used for the production of optically and magnetically active materials, drug delivery, proton conduction, fine chemistry and catalysis, etc. [6-9]. Some of these applications are discussed in detail in subsequent chapters of this book.

As far as synthesis is concerned, synthetic strategies should be easy to apply, simple to reproduce and based on a careful choice of parameters that influence the structure of the material and its properties. Although zeolites can be found in nature, nowadays many zeolites are synthesized in laboratories without having a known natural counterpart. Today, more than 23 o different zeolites are known and classified according to their structural parameters. By contrast, MOF materials are all synthetic, and more than 50,000 structures are registered in the Cambridge Crystal Database [10]. In general, the synthetic strategies concerning zeolites are based on mimicking the conditions under which natural zeolites of volcanic origin are presumably formed, i.e. under elevated temperatures, high salt concentrations and autogenous pressure in hydrothermal conditions [11]. The diversity of existing MOF structures, on the other hand, suggests a wider variety of preparation methods. However, as will be discussed later, the majority of synthetic strategies are based on precipitating the solid from solution. Hence, the aim of this chapter is to survey the synthetic strategies for zeolites and MOFs. This will be accompanied by some examples selected from the most known and used materials of each class. Finally, a brief description of some routine characterization methods applicable to zeolite and MOF materials after their synthesis is presented.

\section{Zeolites}

\subsection{Structure and nomenclature}

Zeolites are crystalline aluminosilicates belonging to the group of tectosilicate molecular sieves. They are porous solids with ordered, interconnected microporous channels with diameters ranging from 0.2 to $2 \mathrm{~nm}$, corresponding to the size of many organic molecules. They possess a well-defined three-dimensional porous structure arising from a framework of $\left[\mathrm{SiO}_{4}\right]^{4-}$ and $\left[\mathrm{AlO}_{4}\right]^{5-}$ tetrahedra $\left(\mathrm{TO}_{4}\right.$, where $\mathrm{T}$ represents $\mathrm{Si}$ or $\left.\mathrm{Al}\right)$ linked together by all their corners, as depicted in Figure 1 a). These primary 
building units (PBU) or blocks are assembled so that each $\mathrm{O}$ is shared by two identical tetrahedra, thus creating a lattice made by identical building blocks, which extends infinitely as it is the case in all crystalline materials. A structure directing agent (named $\mathrm{X}$ in Figure 1) is usually used to guide the self-assembly of $\mathrm{SiO}_{4}$ (red) and $\mathrm{AlO}_{4}$ (blue) units. The nature of $\mathrm{X}$ depends on the zeolite that we aim to prepare and on the synthesis conditions, and can be of organic (amine, alkylammonium or phosphonium ions) or inorganic $\left(\mathrm{Na}^{+}\right)$.

Each $\mathrm{Si}$ ion has its 4+ charge balanced by the four surrounding $\mathrm{O}$ (each with a 2 - charge), so the silica tetrahedron in the lattice is electrically neutral. Since the trivalent $\mathrm{Al}$ is also bonded to four shared oxygen anions, the residual charge on each $\mathrm{AlO}_{4}$ unit is 1-. Therefore, each alumina tetrahedron requires a $1+$ charge from a cation (mono- or divalent) located into the channels or cavities in order to keep the electrical neutrality throughout the structure. After the synthesis of the zeolites these cations are usually sodium or ammonium, but they can be readily replaced by ion exchange. In addition, water molecules are present in the void volume of the cavities and channels.

The unit cell formula of zeolites is usually written as:

$$
M_{x / n}\left[\left(\mathrm{AlO}_{2}\right)_{x}\left(\mathrm{SiO}_{2}\right)_{y}\right] z \mathrm{H}_{2} \mathrm{O}
$$

where $\mathrm{M}$ represents the cation (alkali or alkaline earth metal) counterbalancing the negative charge associated with the framework aluminium ions, $n$ is the charge of the cation, $x$ is the number of Al per unit cell, $y$ represents the number of $\mathrm{Si}$, and $z$ is the number of water molecules entrapped

a

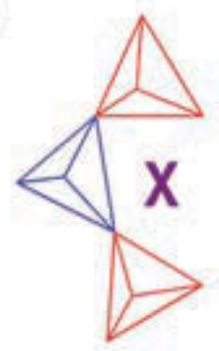

b
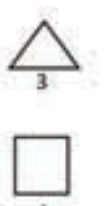

4

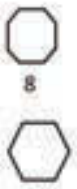

6
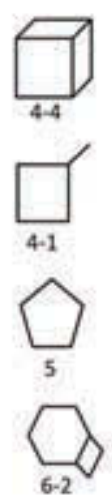
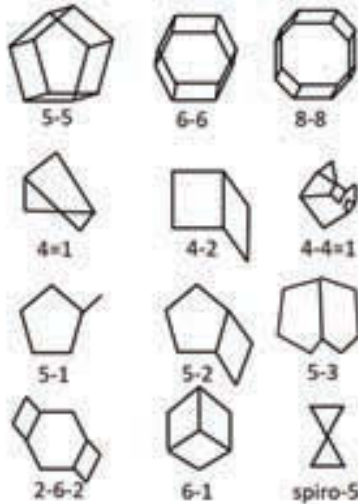
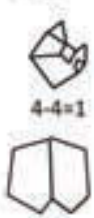

5.3

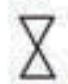

spiro-5

Figure 1. a) $\mathrm{TO}_{4}$ tetrahedra linked together to generate the 3D structure. b) Main secondary Building Units (SBUs). 
(physisorbed) in the channel system. The $\mathrm{Si} / \mathrm{Al}$ mole ratio is always larger than (or equal to) one, since a direct linkage between two $\mathrm{AlO}_{4}$ entities is forbidden, according to Löwenstein's rule [12].

The tetrahedral PBUs are combined in a more sophisticated way to generate repeating structural sub-units. These recurring units are called secondary building units (SBUs). The system of SBUs is quite simple and was therefore adopted as a convenient way for zeolite classification. Figure 1 b) represents sixteen SBUs that actually describe most of known zeolite structures. These SBUs only reflect the aluminosilicate skeleton (i.e. the relative positions of $\mathrm{Si}, \mathrm{Al}$, and $\mathrm{O}$ in space) but exclude the consideration of the cations and water moieties present within the cavities and channels. When SBUs are joined to form infinite lattices, they can define larger rings, containing 6, 8, 10, 12 and up to 20 linked tetrahedra (rings of $\mathrm{T}$ atoms).

The International Zeolite Association (IZA) adopted a classification in which it was assumed that all known frameworks could be described by a combination of one or more SBUs [13-14]. According to the IUPAC, the structure type codes of zeolites consist of three capital letters derived from their original names [15]. These codes have been developed to create a short nomenclature that does not depend on the composition, nature of T-atoms, cell dimensions, or symmetry.

Additionally, zeolites can also be classified according to the size of their pores [16]:

- small pores: six- or eight-membered ring pores (6 to $8 \mathrm{~T}$-atoms) having a pore diameter between $3-4.5 \AA$ (LTA zeolite)

- medium pores: ten-membered ring pores, diameter between 4.5-6 (such as ZSM-5 or ZSM-11, where ZSM stands for Zeolite Socony Mobil)

- large pores: twelve-membered ring or larger pores, diameter between 8 and $20 \AA$ (BEA, Cloverite)

Pore systems may differ considerably between zeolites, depending on the presence of interconnections between the different pore types that may be found in a single structure, ranging from parallel and independent in LTL zeolite (12-membered rings), to $3 \mathrm{D}$ interconnected cage systems, as in FAU (12-membered rings).

\subsection{Synthesis of zeolites}

Systematic synthesis of zeolites started with the pioneering work of Barrer and Milton in the 1950s. Despite hundreds of patents and many papers 
Table 1. Chemical Ingredients Involved In The Zeolite Synthesis.

\begin{tabular}{ll}
\hline Source & Function \\
\hline $\mathrm{SiO}_{2}$ & Building the primary units of the framework \\
$\mathrm{AlO}_{2}^{-}$ & Creating the negative charge \\
$\mathrm{OH}^{-}, \mathrm{F}^{-}$ & Mineralizer \\
Alkali cation: $\mathrm{Na}^{+}, \mathrm{K}^{+}$ & Compensating the charge while avoiding Si polymerization \\
Template: $\mathrm{TPA}^{+}, \mathrm{TEA}^{+}$ & Directing crystallization \\
Water & Solvent, guest molecule \\
\hline
\end{tabular}

published in this field during the last decades, the number of zeolite structures actually known remains low compared to the several million (potentially) stable zeolite structures predicted by computers [17].

Zeolites are traditionally prepared via sol-gel hydrothermal synthesis under autogenous pressure. The chemical sources and their function during the synthesis are listed in Table 1.

The main point of zeolite synthesis is its crystallization from an inhomogeneous gel formed from silica and alumina sources, which were combined with water under high $\mathrm{pH}$ conditions generated by $\mathrm{OH}^{-}$ions. Many parameters need to be controlled, which render the understanding of the zeolite growth mechanisms and crystallization control relatively complex [16].

Little variations of the zeolite synthetic procedures are observed during the last 50 years and all are based on sol-gel hydrothermal syntheses. The application of microwave heating or sonochemistry influences the temperature, time and synthesis duration, although the zeolite formation still occurs under traditional hydrothermal conditions.

$\mathrm{SiO}_{2}$ and $\mathrm{AlO}_{2}$ sources

The silica source is a key parameter, as its dissolution may favour crystallization towards a particular zeolite type. Soluble silicates and their hydrates are widely used, as they can exist in a monomeric form to establish Si-O-Al or Si-O-Si associations [18].

The aluminium source is not so crucial, and most of the laboratories use metal aluminates, commonly sodium aluminate. Zeolite formation is enhanced by the presence of $\left[\mathrm{Al}(\mathrm{OH})_{4}\right]$ moieties at $\mathrm{pH}>10$.

\section{Alkali cations and templates}

The alkali cation acts as a core around which the silica structure is built up. It also interferes in $\mathrm{SiO}_{2}$ polymerization. The template or, more correctly, 
Table 2. Templates reported for the synthesis of ZSM-5 zeolite.

\begin{tabular}{ll}
\hline Tetrapropylammonium halide & Methylquinuclidine \\
Tetraethylammonium halide & Morpholine \\
Tripropylamine & Ethylenediamine \\
Dipropylamine & Diethylenetriamine \\
Propylamine & Triethylenetetraamine \\
1,6-diaminohexane & Ethanol + ammonia \\
1,5-diaminopentane & Ethanol \\
1,6-hexanediol & Ethanolamine \\
Propanolamine & Glycerol \\
\hline
\end{tabular}

the structure-directing agent (SDA), is usually an organic cation containing a functional group able to bind with silicate and aluminate species. The synthesis of "high-silica" zeolites usually requires the presence of an organic structure-directing agent to achieve the desired structure. For example, a wide range of templates can be used to synthesize ZSM-5 zeolite (Table 2).

The template is believed to have two functions when directing the synthesis. Firstly, it promotes the formation of the desired building blocks in the gel. Secondly, it acts as a hydrophobic pore filler, preventing the dissolution and recrystallization of the crystals already formed. In the case of alkylamine salts, the template must be removed after synthesis via Hofmann elimination by calcination at high temperatures $\left(>50{ }^{\circ} \mathrm{C}\right)$.

Figure 2 presents the mechanism of auto-assembly that occurs through van der Waals, hydrogen-bond, and ionic interactions between the hydrophobic silicate species and the template $[19,20]$. The driving force of the process is the replacement of water molecules by Si and $\mathrm{Al}$ moieties around the organic cation. This mechanism is quite different from any mechanism encountered in classical organic chemistry, since no other reactants and other pathways are available to reach the desired product. The structuredirecting agent acts as a template for the zeolite cavities and can be chosen to tailor the pore openings.

In addition to the SDA, co-templates can also be added in the synthesis. One remarkable example is the synthesis of mesoporous LTA zeolite by Choi et al. [21] with the incorporation of a surfactant in the synthesis gel. Sophisticated morphologies have also been obtained by Valtchev et al. [22], who added a leaf of Equisetum arvense to the gel, thus enabling replication of the plant's surface morphology. Likewise, sugar cane bagasse 

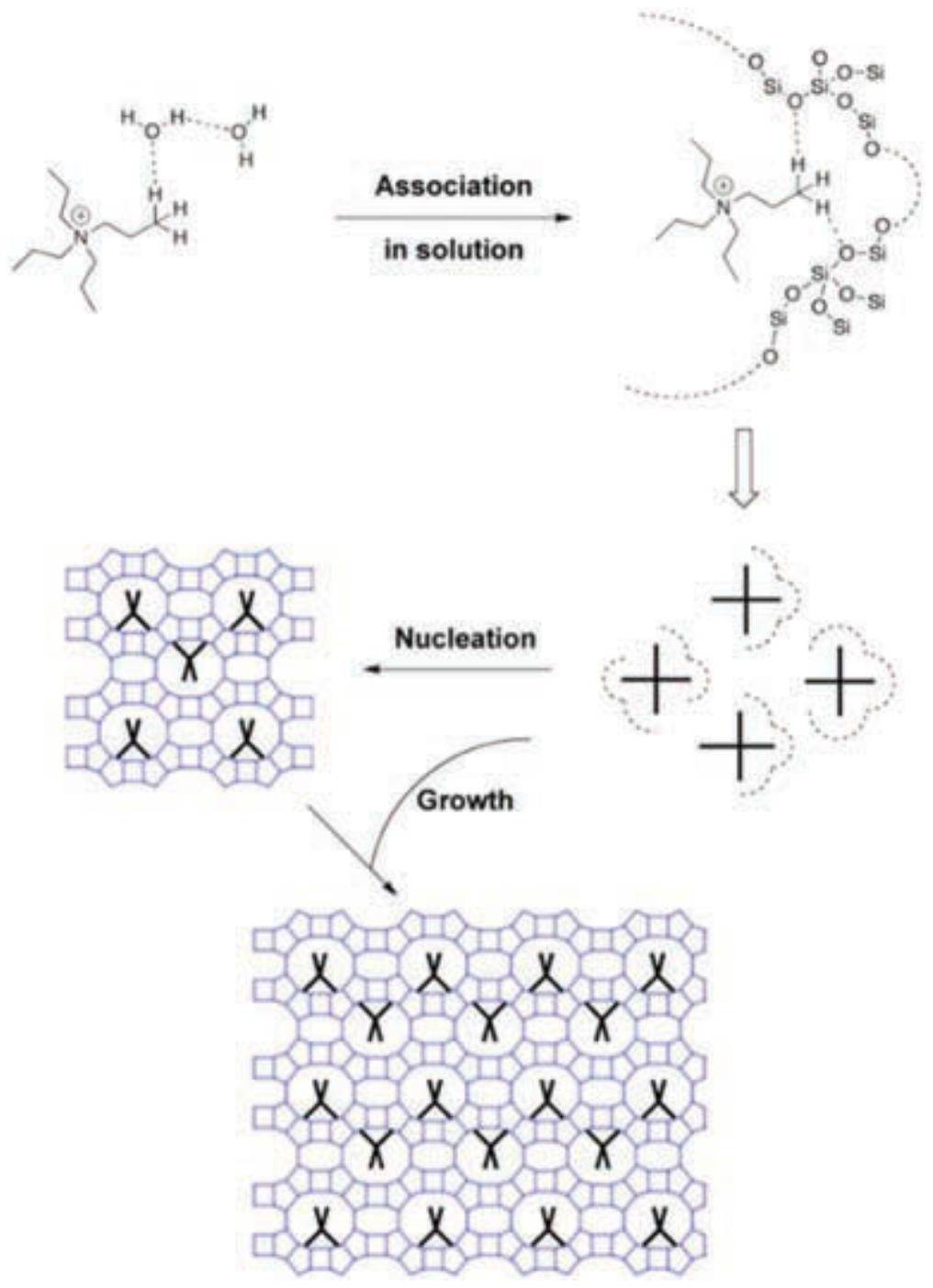

Nucleation
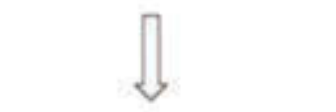

Figure 2. Mechanism of structure-directing action and crystal growth involving combined inorganic-organic species in ZSM-5 zeolite synthesis reprinted with permission from [19]. Copyright 1995 American Chemical Society.

residues were successfully used to produce MFI zeolite crystals exhibiting a nano-"French fries" morphology [23].

\section{$\mathrm{OH}^{-}$}

Since the $\mathrm{pH}$ is often higher than 10, hydroxyl anions act as the mineralizer, a nucleophile that influences the crystallization time. In general, crystallization 
of zeolites happens from an inhomogeneous hydrogel, formed by the T-sources ( $\mathrm{Si}$ and $\mathrm{Al}$ ), the mineralizing agent, and the SDA via a supersaturated solution, favouring the nucleation of initial nuclei that then grow to form larger crystallites [24]. Once, the concentration shifts below the supersaturation limit, no new nuclei are formed and the present crystallites continue to grow as long as T-sources are available. It is important to note that complex dissolution-recrystallization processes occur parallel to crystal growth [25].

\section{Fluoride media}

$\mathrm{F}^{-}$ions can be used instead of $\mathrm{OH}^{-}$anions as the mineralizer and it thus becomes possible to synthesize zeolites at $\mathrm{pH}$ values in the acidic range $[26-32]$. These conditions are particularly appropriate for the synthesis of high-silica materials. The fluoride route is the best strategy to produce highly crystalline materials exempt from defects [32]. The crystallinity of the materials produced in fluoride media is generally higher than that for materials obtained by the hydroxyl-mediated route. In addition, [F]-ZSM- 5 zeolites exhibit a regular and narrow crystal size distribution in the 1 to $100 \mu \mathrm{m}$ range. This larger crystal size as compared to that arising in the alkaline route is due to the growth in a less supersaturated solution. Here, fewer metastable phases are formed, which implies a certain ease of preparation of the desired zeolite.

Another important advantage is the direct formation of the ammonium form $\mathrm{NH}_{4}-\mathrm{ZSM}-5$ form, rather than Na-ZSM-5, which has to be subjected to repeated ion-exchange steps. In this procedure, a single calcination step is needed to burn the template and to generate the catalytically active acidic $\mathrm{H}-\mathrm{ZSM}-5_{5}$ form.

This "unconventional" procedure also offers the possibility for an incorporation of doping elements such as $\mathrm{Fe}^{3+}, \mathrm{Co}^{2+}$ or lanthanides, which are sparingly soluble in alkaline media.

Reaction variables: concentration, temperature, pressure and time Not only the presence of all components in the reaction mixture is important, but also their relative proportion. A required $\mathrm{Si} / \mathrm{Al}$ zeolite composition can be obtained only by using an appropriate template and/or an adequate $\mathrm{OH}^{-} /$ $\mathrm{SiO}_{2}$ ratio. If the latter increases, more silicate remains in solution and lower $\mathrm{Si} / \mathrm{Al}$ products are formed. Additionally, the $\mathrm{H}_{2} \mathrm{O} / \mathrm{SiO}_{2}$ ratio impacts the formation of any zeolite structure, affecting the degree of polymerization. The proper combination of all these parameters is not trivial [25,33]. Figure 3 shows a typical phase transition diagram as a function of composition.

Several studies highlighted the influence of synthesis duration and temperature over the metastability of the zeolites $[34,35]$. Zeolites crystallize from alkaline aqueous gels at temperatures ranging from room temperature 


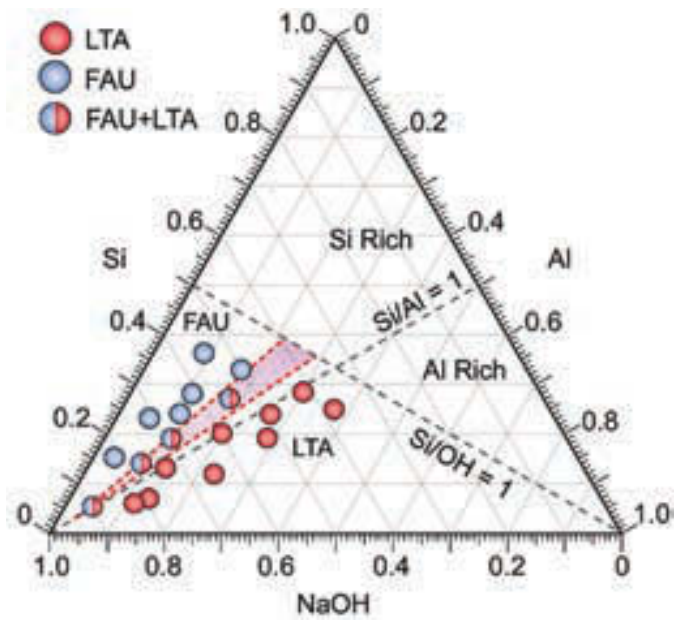

Figure 3 .Typical zeolite crystallization domain showing the phases formed from gels with different composition at a given temperature and synthesis time reprinted with permission from [25]. Copyright 2013 American Chemical Society.

to $300{ }^{\circ} \mathrm{C}$. Therefore, the syntheses are most often conducted in sealed vessels under autogenous pressure, i.e. that generated by the vapour phase when the temperature is raised.

Time is another key variable. It is important in two ways: i) an induction period during which the mixture is held at ambient temperature (gel ageing) favours the synthesis yield, ii) in some cases, different metastable structures can be formed depending on time (e.g. Mordenite vs. analcime). Ostwald's law states that transformations have to occur in the direction of more highly stabilized phases [36].

Despite a long debate regarding the mechanism(s) of crystallization, significant advances have been achieved, thanks to contributions like those of Valtchev and Mintova [16,37-39]. On a general consensus, zeolites are synthesized from aluminosilicate gels in which structural and chemical rearrangements occur, allowing (under suitable conditions) nucleation and crystallization into highly organized structures $[16,40]$.

A typical S-shaped curve usually is observed when plotting the yield of crystalline material against synthesis time [36]. When the synthesis mixture reaches the temperature necessary for zeolite formation, crystallization can only be expected after an induction period during which nucleation occurs. In fact, the state of nucleating solutions at times prior to the development of periodicity has become accessible by spectroscopic techniques such as NMR and X-ray scattering [40-42]. It was shown that at this stage, the SBUs later forming the crystal still are species in solution [43]. The gel 
and the species in solution thus continuously rearrange, changing phases from monomers to clusters of silicates and aluminosilicates. These clusters form and disappear by condensation and hydrolysis under the influence of temperature. In this re-organization process some particles become stable and small nuclei (in the nanometer range) are formed before crystallization (and crystal growth) can start. All these features suggest that crystal growth is preceded by a slow nucleation step initiated by local concentration fluctuations inside the mixture and followed by a spontaneous growth of nuclei exceeding a critical size [40]. Pope has explained this phenomenon in terms of a decrease in the Gibbs free energy, which favours crystal growth [44].

According to Ostwald's law of successive transformations, the first product to appear in the course of a zeolite synthesis may not be the more stable [37]. In other words, a non-stable system does not necessarily transform into the most stable state but rather into one close to its own, and so on. It means that in zeolite synthesis, a series of kinetic products may form as transient meta-stable phases, prior to the formation of the most stable thermodynamic product [45]. The corollary is that a minor modification in the gel, which represents a large panel of variables, may allow shifting from one structure to another. Likewise, the possibilities for tailoring any zeolite intrinsic properties are nearly infinite, since the set of synthesis parameters is wide [46]. Quite often, a "seeding" technique is applied to guide the crystallization towards the desired material, i.e. a few milligram of the desired zeolite are added to the synthesis mixture.

The synthesis of a zeolite occurs through weak and strong interactions between building units, forming covalently bonded framework stabilized by extra-framework species. The mineralizer and the organic template (and co-template) play a role in determining the size of the precursor particles in the gel. Subotic et al. [47-51] have demonstrated that different kinds of solid particles were present in the hydrogel before and after hydrothermal treatment: aggregates of amorphous gel particles, partially ordered particles, aggregates of fully ordered particles. During the initial (alumino) silica polymerization stages, small randomly aggregated gel particles were shown to form [16]. The composition of the gel particles approaches the stoichiometric zeolite composition once a chemical equilibrium between solid and liquid phases achieved. In summary, the zeolite organization proceeds through: i) formation of primary units (precursor species), ii) aggregation of those species and their densification resulting in amorphous particles, whose size and morphology are indicative for the preparation of zeolites with similar properties, iii) further nucleation occurs on the amorphous particles and the crystal growth continues within the particles followed by the addition of primary units (or aggregation of nanoparticles) to the 


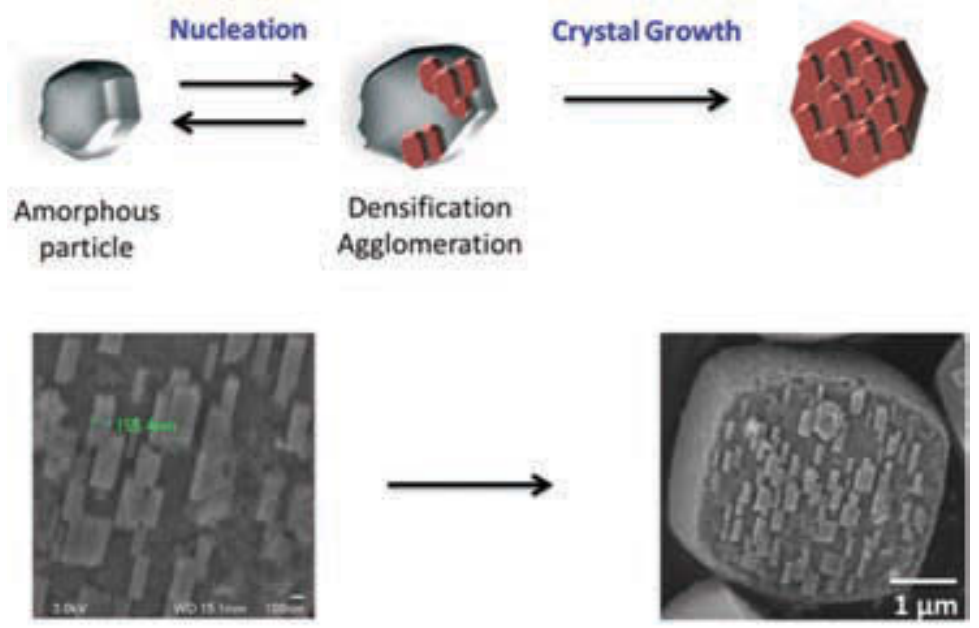

Figure 4. Scheme of an aggregation mechanism for zeolite crystal growth (top) illustrated by a homemade zeolite synthesis (bottom).

growing crystal with time. Figure 4 provides a schematic overview of an aggregation mechanism inspired by Davis' studies [52]. SEM images of a homemade zeolite illustrates suggestions from Mintova and Davis $\left[16,5^{2}\right]$.

In view of the numerous structures, compositions and synthesis conditions that may exist, a universal mechanism that can explain all zeolite crystallization modes does not exist. Whilst a solution-mediated process has been discussed for many years, the existence of solid-solid transformations in the gel represents nowadays a well-established route. Still a proper control of the structure at the nanoscale remains the key for tailoring zeolite properties and structure at the molecular and microscopic levels.

\section{Metal-organic frameworks}

\subsection{Structure and nomenclature}

In the development of the metal-organic frameworks the know-how gained from zeolites served, with no doubt, as inspiration. Since the discovery of zeolites, and especially since the mastery of their synthesis and application in shape selective catalysis, chemists dream of well-defined porous structures. This quest led to a constant emergence of novel materials with potential catalytic applications and other fields of porous materials evolved, such as mesoporous materials, hierarchical systems, and metal-organic-frameworks (MOFs). 


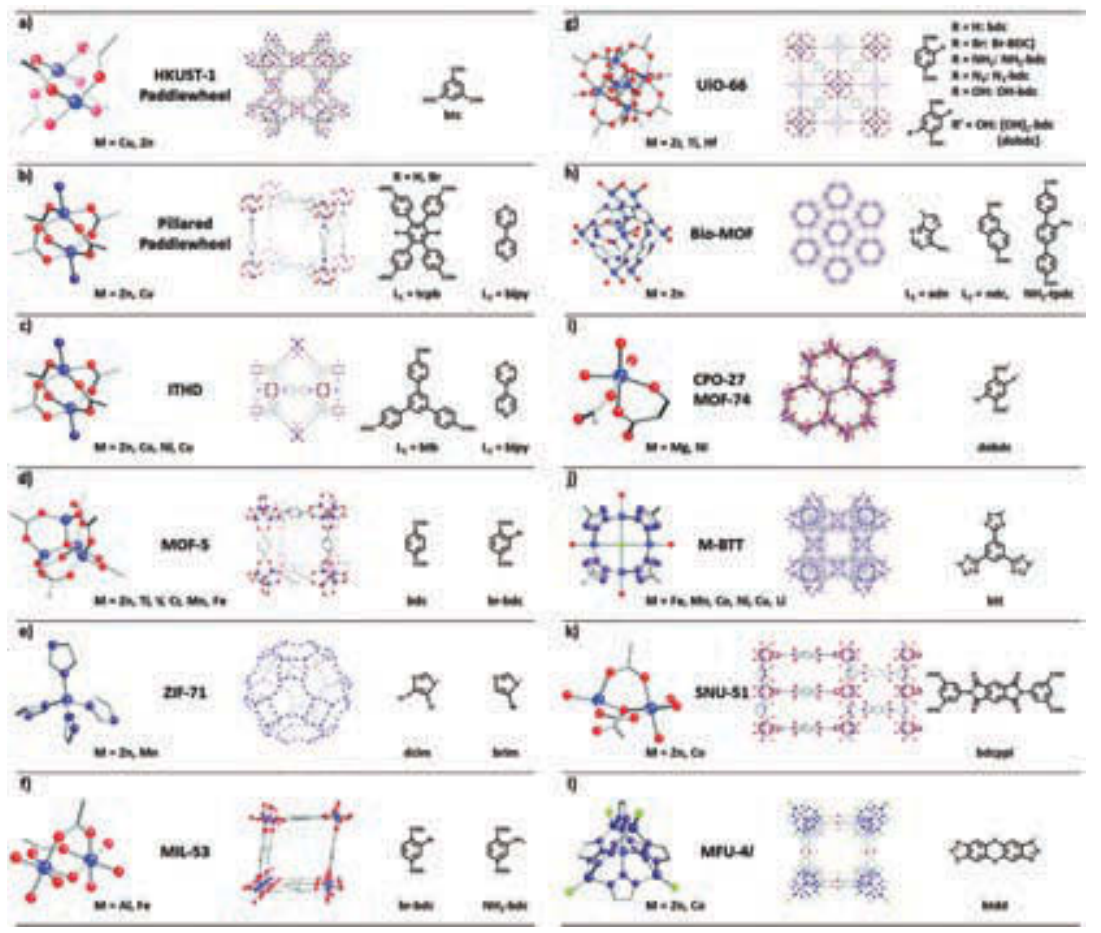

Figure 5. Lattice structures (middle) and corresponding SBUs (metal nodes (left), and organic linkers (right) of some MOFs. Atom definition: blue - metal, red - oxygen, purple - nitrogen, grey - carbon, green - chlorine). [53] - Published by The Royal Society of Chemistry.

Metal-organic frameworks, also called coordination polymers (CPs), are a type of hybrid organic-inorganic solid built up by an extended network of metal ions (or clusters) coordinated to multidentate organic molecules. This definition englobes materials with different crystallinity, chemical nature and porosity [8]. As for zeolites, metal-organic components form extended $3^{D}$-skeletons by association of secondary building units (SBU). Whereas zeolites contained only inorganic parts (namely $\mathrm{SiO}_{4}$ and $\mathrm{AlO}_{4}$ tetrahedra), a MOF SBU contains organic linkers bonded to a metal centre through covalent bonds. Figure 5 present some examples of MOF SBU.

The abbreviation MOF is used as a general term of this class of compounds, although it also designates a subclass of different compounds when combined with a number (MOF-74, MOF-101, MOF-177, etc.). Analogously to zeolites, existing MOFs are grouped in families of compounds, designated by a name and a number. The families are organized either by similarity in structure and symmetry, like IRMOFs (IsoReticular Metal-Organic Frameworks) and F-MOF-1 (Fluorinated Metal-Organic Frameworks), by similarity to zeolite topology, like 
ZIF (Zeolite Imidazole Framework), or by abbreviations corresponding to the place of their discovery, like MIL-53, MIL-101 (Materials of Institute Lavoisier) or HKUST (Honk Kong University of Science and Technology).

MOFs are generally sought for their porosity, therefore, the type and size of the SBU employed is the predominant parameter to be controlled. The openness of the framework is ensured by the use of organic ligands that confer a rigidity and allow the control of the pores such that "the larger the brick, the larger the pores" [1] as illustrated in Figure 6. However,

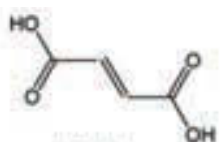

FMA

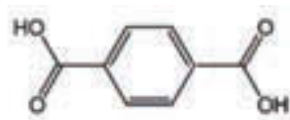

BDC

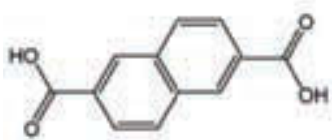

NDC

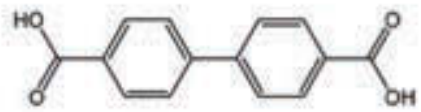

BPDC

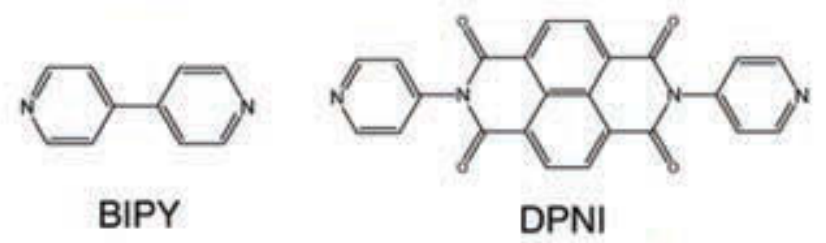

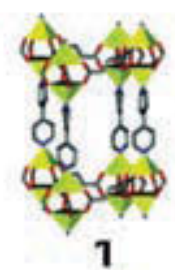

1

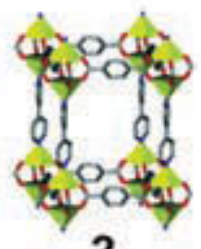

2

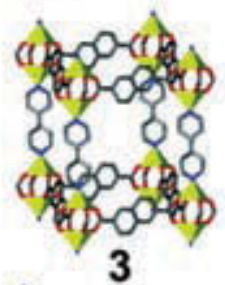

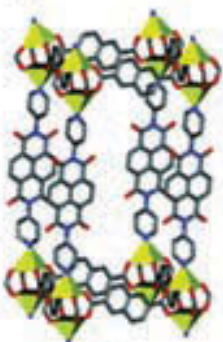

4

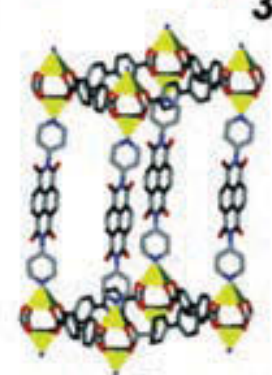

5

Figure 6. Single network units for compounds 1-5. The yellow polyhedral represent the zinc ions. Carbon: gray. Oxygen: red. Nitrogen: blue. Reprinted from ref [56] with permission. Copyright 2005 American Chemical Society. 
large organic linkers could weaken the structure or diminish its porosity through lattice self-interpenetration [54,55]. To palliate those problems the employed synthetic procedure plays a key role.

\subsection{Synthesis of MOFs}

The different preparation methods available for MOFs can be divided into two groups: traditional synthesis, usually referring to classical precipitation

and hydro/solvothermal method, and non-traditional methods, including microwave and ultrasound-assisted syntheses, mechanochemical and microemulsion methods.

\section{Traditional methods}

The precipitation from solution, also called one-pot, occurs at room temperature or upon heating from the mixture of metallic precursor and organic linkers in adequate solvent at $\mathrm{pH}$ and saturation concentrations adequate for MOF precipitation.

The easiest synthetic approach is performed at ambient pressure and temperature, although it sometimes results in poor crystallinity and reproducibility. Nevertheless, it has the advantage of allowing rapid MOF isolation and avoiding energy consumption. Almost all existing MOFs structures are prepared at least once using this method.

The second method in this group, the solvothermal method, has similar parameters to those in the sol-gel hydrothermal synthesis of zeolites. It implies the use of solvent above its normal boiling point in a hermetically sealed chemical reactor. The method results in high product yields and crystallinity and surpasses by far the reproducibility of the one-pot synthesis. Similarly to zeolite synthesis, a successful application of the solvothermal method to the MOF synthesis depends on reaction variables (temperature, time...), concentration and solubility of the precursor in the solvent, etc. The framework's self-assembly is greatly influenced by the characteristics of organic ligand, the coordination nature of the metal ions and the behaviour of the solvent, the $\mathrm{pH}$ of the solution, and by the presence or not of the template.

Unlike zeolite synthesis in which a directing agent is usually added to the precursors mixture, in the solvothermal approach this role can be assumed directly by the solvent. The organic molecules present in the synthesis (solvents, $\mathrm{pH}$ controllers like amines, templates if any, etc.) can play different roles in the MOF structure formation: i) as a solvent or deprotonation 
agent, ii) as a template (with a functions similar to the zeolite templates), and iii) as a coordinating ligand to the metal ion [57]. Not only the crystallinity but also the type of structure obtained can be influenced by changing the operational parameters, like temperature and duration. The latter is considered to be a disadvantage of the traditional methods of synthesis, in which several days are sometimes necessary to achieve acceptable product qualities. Long synthesis duration also involves higher expense, since highly energy-consuming processes and equipment (pressure-sealed vessels) are required.

\section{Microwave- and ultrasound-assisted processes}

Though quite different in nature, both methods provide ways to accelerate MOF's formation rate in comparison to traditional methods. Microwave (MW) heating offers a reduction of the synthesis duration by increasing the efficiency of heating. It has been reported that MW heating provides energy to overcome the activation energy barrier for the framework assembling. MW also influences the metastability of the system and its reactivity in a way that, the less stable the system, the higher the reactivity of the components and the faster the rate of MOF formation [58]. For example, Zou et al. [59] reported an unusually short time for HKUST-1synthesis by microwave irradiation (20 minutes rather than 8 hours in traditional hydrothermal synthesis), which was due to a faster nucleation rate rather than faster crystal growth. Schlesinger et al. [6o] evaluated several synthetic methods for $\left[\mathrm{Cu}_{2}(\mathrm{btc})_{3}\left(\mathrm{H}_{2} \mathrm{O}\right)_{3}\right]$ and $\left[\mathrm{Cu}_{2}(\mathrm{btc})\right.$ $(\mathrm{OH})\left(\mathrm{H}_{2} \mathrm{O}\right)$ ] formation. The microwave-assisted solvothermal method was the fastest one for pure $\left[\mathrm{Cu}_{3}(\mathrm{btc})_{2}\right]$ with high BET surface area and specific pore volume when DMF was used as the solvent. The choice of solvent is probably the most important variable to be controlled in this method. The solvent should absorb the microwave radiation and convert it to heat unless a metastable point of the system can be achieved at near ambient temperature.

Microwave-assisted MOF synthesis is considered a very simple and energy-efficient strategy to obtain these materials. It is easy to control, reduces crystallization times and increases the yield to solids. This method also promotes nanocrystals formation through a rapid and uniform nucleation, which is a consequence of the formation of local hot-spots and a fast heat transfer within the reaction media [61].

The ultrasound-assisted process (sonochemical synthesis), on the other hand, increases the area of contact between the reactants and, as a consequence, increases the rate of nucleation and crystal formation. In addition, 
the release of air bubbles formed by the decrease of the pressure in the liquid under condition of acoustic wave propagation disintegrates the particle agglomerates and results in an homogeneous particle size produced in short reaction times. Armstrong et al. [62] studied the crystallization mechanism of HKUST-1 under sonochemical conditions and found that crystallization initiates in spontaneous super-saturation points along the shockwaves generated by the implosion of the bubbles. Crystal growth followed a simple solid-on-solid model at high reactant concentrations and relatively low energy levels, thus shortening the time of synthesis, currently to less than 30 minutes for the formation of Zn-HKUST-1 and Cu-HKUST-1 nanorods at room temperature and ambient pressure [63]. It is clear that both microwave- and ultrasound-assisted methods are very suitable for the preparation of nano-MOF materials [64].

\section{Mecanochemical synthesis}

As a solvent-free method, mecanochemical synthesis has successfully found its place within the recently reported methods for MOF preparation $\left[61,65^{-67}\right]$. This method consists of a solid-solid reaction initiated by mechanical energy, usually ball milling. The rise of pressure or temperature is not required but sometimes a secondary phase can be obtained making difficult the isolation of the products. However, the presence of a small proportion of liquid component (not a solvent) could offer some benefits, such as an easier crystallization and higher yield of the desired product due to the improved mobility of the species and their homogenization [10]. Klimakow et al. [67] synthesized significant amounts of high quality HKUST-1 through a mechanochemical approach, proving that the procedure was reliable, effective and very fast (25 minutes). Nevertheless, they found some pore blocking effect from unreacted molecules, which can be removed in an adequate activation treatment. Still, this method is limited to MOFs whose synthesis is normally made under mild conditions and excludes interesting systems based on $\mathrm{Fe}, \mathrm{Cr}, \mathrm{Al}$ or $\mathrm{Ti}$ [64].

\section{Microemulsion synthesis}

This approach is based on the microemulsion formation, i.e. thermodynamically stable dispersions of immiscible liquids (water and oil phases) and the presence of emulsifiers or surfactants. The emulsifier is a molecule presenting both polar and non-polar parts. In very diluted water or oil solutions, the emulsifier exists as monomer, but when its concentration exceeds a certain concentration, called critical micelle concentration (CMC), the emulsifier molecules associate to form aggregates, that is, micelles [68]. 
These micelles are considered as nanoreactors wherein MOF formation reaction takes place. Thus, the size and the morphology of the resulting MOF particles are greatly influenced by the water/oil phase ratio and the surfactant concentration [69-71].

Other synthetic strategies are also available in the literature and may offer different advantages depending on the MOFs desired structure. It is worth mentioning the electrochemical method, in which metal ions are homogeneously supplied by the dissolution of an anode. It is reported as a very clean and fast method but it is generally restricted to $\mathrm{Cu}$-containing MOFs, like HKUST [72,73]. The continuous flow production method should be noted as the first one applied for large-scale industrial preparation. It is based on the induced crystallization from a stream of dissolved precursors in organic solvents. Finally, we should also mention the developing field of post-synthetic transformation, which is based on the transformation of already prepared MOFs into a novel structures, some of which cannot be accessed using the previous methods [74].

No matter the time or the energy involved in the synthesis, before starting one must remember the basic requirements: i) the adequate selection of salts and linkers, ii) the manner in which they connect together to obtain a possible porous structure, and iii) the necessity of a purification or activation step after the preparation. These steps are as important as the choice of the synthetic strategy.

All changes produced in a function of synthetic parameters variations should be controlled and this control is usually assured by the use of sample characterization techniques. This characterization should include structure identification, by X-ray diffraction analysis, and morphological and elemental analysis, which can be obtained by electron microscopy.

\section{Standard characterization for structure, texture and morphology}

As mentioned above the study and comprehension of physicochemical properties are of paramount importance to modulating the synthesis protocols in order to obtain solids with the adequate morphology, texture and structure. Standard characterization methods for the structure, texture and morphology of MOFs and zeolites include: powder X-ray diffraction (XRD), Brunauer-Emmett-Teller (BET) surface area measurement, and electron microscopy techniques. It should be emphasized that the use of a single method is insufficient for the analysis of a MOF or zeolite. Therefore, 
elemental analysis, IR spectroscopy, NMR and others are normally used in combination with the above methods.

\section{Powder X-Ray diffraction}

Zeolites and metal-organic frameworks are, by definition, crystalline solids, that is, they have a long-range atomic or molecular order. Thus, powder $\mathrm{X}$-ray diffraction (XRD) is typically the first method used for their identification, as each crystalline solid phase has its own characteristic XRD pattern as a "fingerprint". XRD is a routine, non-destructive characterization technique with high sensitivity, reliability, and easy sample preparation and data interpretation $\left[75^{-78}\right]$.

XRD measurements give information on the solid structural organization, proportion and size of the crystalline structures, spacing between the lattice planes, preferential order and growth of the crystallites $[78,79]$. For zeolites and metal-organic frameworks, this also includes framework topology and extra-framework cations and/or adsorbed molecules positions. The presence of the latter influences the adsorption and catalytic properties of the materials through their interactions with the guest species [8o-82]. The purity of the sample can also be revealed by considering the proportions and compositions of other phases, if present. Figure 7 shows some powder XRD patterns of different materials and their corresponding electron microscopy images.

Zeolite families present very distinct patterns $[83,84]$. To identify the precise structure, XRD patterns are compared to reference patterns of known zeolite structures. The unit cell composition of a zeolite can be directly determined and its reference patterns can be found in the Atlas of
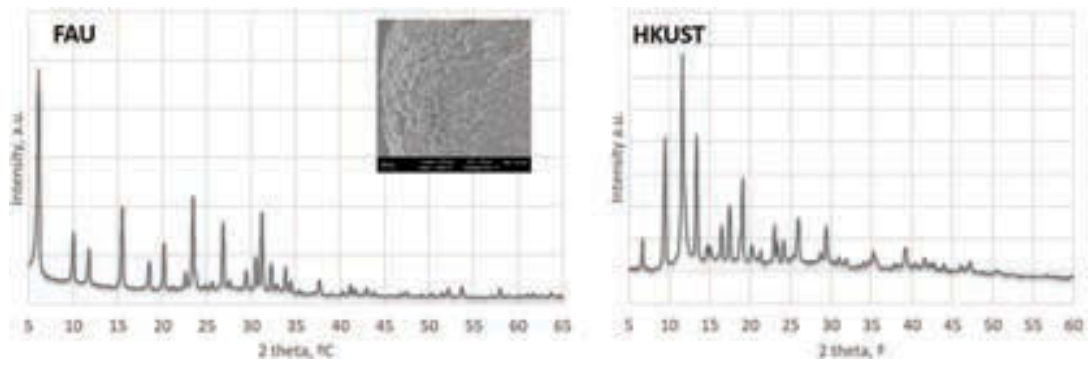

Figure 7. Examples of basic structural and morphological characterization. Simulated XRD analysis for zeolite FAU and H-KUST MOF. Insert: 'French fries' MFI structure. 
Zeolite Framework Types [85] or in the Collection of Simulated XRD Patterns for Zeolites [86]. The powder diffraction data and simulated patterns for the reference structures are listed alphabetically according to the respective framework type code [87]. Materials with the same framework code (i.e. framework topology) but different composition will have more or less different diffraction patterns; therefore, several reference materials may be found.

On the other hand, the width and shape of the diffraction peaks is also significant and are a convolution of effects due to crystallite size, strain, and instrumental broadening. The Scherrer equation normally relates the diffraction peaks widths to the average (by mass or volume) crystallite dimension [76]. Certain zeolites often present highly isotropic crystals, especially those with cubic symmetry like zeolites A, X, or Y [88]. However, other zeolites present highly anisotropic dimensions. Many one-dimensional pore zeolites tend to possess needle- or rod-shaped crystals. In catalytic or adsorptive applications, it may be desirable to have crystallites that are short in a particular direction in order to create the most efficient access within the pores of the solid. Characterizing the crystallite dimensions is therefore relevant in the interpretation of their behaviour.

The powder XRD diffraction analysis applied to MOFs allows for the drawing of conclusions concerning the reproducibility of the synthetic procedures and could explain structural differences between samples of the same MOF prepared by different methods [89]. Small variations in the synthetic conditions often influence MOF crystallization but may also result in the appearance of other polymorphic phases. Combined experimental and computational studies can be used to identify the driving forces in the formation of the different crystal phases [9o]. It is usual to employ simulated powder XRD patterns calculated from model crystal data [91] and to compare them with experimental MOF patterns [92,93] directly or by Rietveld refinement analysis [94,95]. Using this method, a reference pattern for the model crystal is calculated and then compared to the experimental data. A fitting algorithm allows us to refine the model and obtain precise values for the lattice parameters, crystal densities, degree of crystallinity, and crystallite size. Nevertheless, MOFs crystal structures are not always unambiguously determined. Although XRD is widely employed and well understood, the structure elucidation is not always a straightforward process. The large unit cell parameters of MOFs and the high electron density on the metal sites can make it challenging to determine its structure by X-ray diffraction.

The thermal stability, an important characteristic of MOFs, [96] can be also analyzed by X-ray diffraction analysis as temperature is increased. 
Heating MOFs induces evaporation of the solvent, hosted in the porous structure of the solid. As a consequence, the MOF structure changes: structure shrinks and metal-containing secondary building units convert to metal oxides. A complementary method for studying the thermal stability of MOFs is thermogravimetric analysis (TGA) [97], which measures the mass of an analysed sample as a function of temperature to determine the thermal decomposition of the sample. It also allows for the establishment of a purification and activation protocol. Moreover, if the thermogravimetric analysis is combined with a mass spectrometer it is possible to determine the temperature at which the sample changes and to quantify the solvent removal and the stability of the structure under heating.

\section{Adsorption and surface area measurement}

Properties, such as surface area, pore volume and pore-size distribution are essential parameters, especially in shape selective catalysis and adsorption. The reactants must run across the porous system to reach the catalytically active sites and the resulting products have to leave the sites. These mass transfer processes depend on the pore size, i.e. bulk diffusion in large macropores (diameter $>50 \mathrm{~nm}$ ), Knudsen diffusion in mesopores (diameter $2-50 \mathrm{~nm}$ ) and configurational diffusion in the micropores (diameter $<2 \mathrm{~nm}$ ) [98]. Generally, the physical adsorption of a gas [99-101] is routinely used to characterize porous materials. This technique accurately determines the amount of gas adsorbed by the solid material, an indirect measure of the pore properties and structure. The starting point of the BET analysis is a determination of the adsorption and desorption isotherms, which are represented as the amount of probe gas adsorbed as a function of its relative pressure (the ratio of its partial pressure to its vapour pressure) at a fixed temperature. Different probe gases including $\mathrm{N}_{2}, \mathrm{Ar}$, and $\mathrm{CO}_{2}$ are frequently used as probe gases, depending on the nature of the material (adsorbent) and on the information required [102-104]. $\mathrm{N}_{2}$ adsorption at $77 \mathrm{~K}$ at sub-atmospheric pressures is frequently used as routine quality control. If applied over a wide range of relative pressures, $\mathrm{N}_{2}$ adsorption isotherms can provide information on the pore size distributions in the whole range of porosity of the material: micro-, meso- and macroporosity (approximately 0.5-200 $\mathrm{nm}$ ) [105].

Valuable information can be deduced from the shape of the nitrogen adsorption/desorption isotherms. According to IUPAC classification, six types can 
be distinguished, although only four are usually found in routine characterization [105]. Type I isotherms are characteristic of microporous adsorbents, such as zeolites, and Type IV are typical of mesoporous solids. The latter is characterized by an increase in the adsorbed gas volume at high $\mathrm{p} / \mathrm{p}_{\circ}$ and by the existence of a hysteresis loop. The presence of hysteresis in the isotherms indicates the presence of mesopores and its shape is related to the shape of the mesopores [106]. Roughly, a vertical loop indicates cylindrical mesopores, whereas a more horizontal one indicates ink bottle-type mesopores. The increase of the adsorbate volume at low $\mathrm{p} / \mathrm{p}$ 。 pressures in the type IV isotherms indicates the presence of micropores along with the mesopores. Experimentally, micropores can be analysed by adsorption calorimetry coupled with isotherm measurements or by pre-adsorption of large molecules [99]. The determination of the micropore size distribution in zeolites is preferentially performed using $\mathrm{Ar}$ adsorption at $87 \mathrm{~K}$ (or $77 \mathrm{~K}$ ). The use of $\mathrm{Ar}$ is justified as $\mathrm{N}_{2}$ presents quadrupolar moment causing an enhanced interaction with the zeolite framework and hindering discrimination of different pore sizes [101]. In addition, $\mathrm{N}_{2}$ adsorption in micropores occurs at lower $\mathrm{p} / \mathrm{p}$ o values than $\mathrm{Ar}$, the latter being thus more favourable for accurate measurements of smaller micropores [107].

BET area is a measure of the total area of the solid (micro-, meso-, and macropores). It is based on the multilayer adsorption model proposed by Brunauer, Emmet and Tellet (BET), applied to adsorption data in a suitable range of low pressures. If the cross-section area of the adsorbate is known (e.g. $0.162 \mathrm{~nm}^{2}$ for $\mathrm{N}_{2}$ ), the area of the solid can be estimated.

MOFs surface areas can be also calculated geometrically from the corresponding crystal structures [108]. In this sense Walton and Snurr [109] simulated nitrogen isotherms in a series of MOFs and showed that the accessible surface areas agree very well with the BET surface areas obtained from the simulated isotherms, thus demonstrating that the use of this method is physically meaningful for MOFs characterization [110].

The t-plot and s-plot are empirical methods that allow a semi-quantitative analysis of the micropore surface area [111]. Both methods are based on the comparison of adsorption isotherm data of porous sample to a nonporous one (type II) of comparable chemical composition and surface properties. The t-plot is the representation of the amount of gas adsorbed $v s$. the statistical thickness that the adsorbate would have at the same relative pressure on the nonporous sample. By fitting it to a straight line, estimates of the mesopore surface area and of micropore volume can be obtained from the slope and intercept, respectively [112].

Several methods to calculate the pore-size distribution from adsorption/desorption isotherms have been developed. The Barrett, Joyner and 
Halenda $(\mathrm{BJH})$ model is commonly used for the mesopore range and part of the macropore range $[105,100]$. It uses the desorption branch of the isotherms to calculate the pore size distribution and the adsorbed volume. It is designed as an ASTM standard method D 4641/87, and based on the modified Kelvin equation for capillary condensation. The method gives a reasonably good pore size distribution up to $c a .4 \mathrm{~nm}$ diameter. However, below a pore diameter of $2 \mathrm{~nm}$ the Kelvin equation is not valid [113-114].

Due to the size and regular nature of their pores and apertures, one of the most important zeolite functions is to serve as a molecular sieve. Depending on the pore system of the zeolite, molecules can penetrate into the channel network or can be excluded from it. However, sometimes the transport of reactants to the active sites or the counter-diffusion of products in the channels is difficult and leads to intracrystalline transport limitations [115]. Development of more open structures by creating additional porosity, e.g. by combining micro- and mesopores is a well-known approach to improving zeolite difusional properties [115-116].

MOFs are characterized by the diversity of their structures, different symmetries and pore sizes. The chain length of the linker conditions their pore size, while the introduction of substituents and functional groups into the linker provides additional selectivity and chemical properties in the pores [117]. MOFs are one of the known materials with the highest specific surface area, some of them presenting BET specific surface area values close to $6000 \mathrm{~m}^{2} \mathrm{~g}^{-1}$ [118-119]. The post synthesis treatment of the frameworks (catenation) and the presence of organic or inorganic species hosted in the pores can greatly reduce these surface areas [89,102]. For instance, Kaye et al. [120] obtained extremely porous $\mathrm{MOF}-5$ by minimizing its exposure to atmospheric or solvent molecules during the preparation. They also report as a possible reason for MOF- 5 surface loss: the framework decomposition under exposure to water and humid air during and after the synthesis procedure.

\section{Electron microscopy}

Zeolites may have different dimensional channels and may exist in a variety of morphologies [121-123]. They can exist as relatively large crystals of ca. $1 \mu \mathrm{m}[124]$ and, in this case, scanning electron microscopy (SEM) can provide useful information about morphology, defect presence and growth mechanism, as presented in Figures 4 and 7. For both zeolites and MOFs SEM can be used to monitor the presence of mesopores and the quality of the crystals [125]. However, when the features are around $1-3 \mathrm{~nm}$, the use of 
TEM microscopy is better suited. The first works to describe the usefulness of transmission electron microscopy (TEM) for extracting morphological and structural information date from the 1940s [126-127]. Nowadays TEM is considered a powerful characterization technique providing fundamental information on morphology and microstructure [126]. The structures of defects (e.g. dislocations, stacking faults, twins, etc.) can be also characterized [124]. TEM can also show the effects of dealumination of the zeolite structure [128] or reveal the porosity in three dimensions by means of rotation and image reconstruction (tomography) [129] and even locate positions of metal particles within the pores [130].

Microstructure characterization is crucial for the understanding and optimization of zeolites and MOF synthesis. For multicomponent solids, in general, proper mixing of the components is of crucial importance. The presence of phases other than the desired ones can influence in a great manner the properties of the material and therefore its applications. On a macroscopic scale the control of "mixing" is usually obtained by using "bulk" techniques such as X-ray diffraction or vibrational spectroscopy [92]. In many cases, however, local information at the nanometer scale is desired. TEM is the method used for that purpose, providing direct imaging, electron diffraction patterns and X-ray fluorescence spectroscopy of specific sample points with high spatial resolution [131]. When high resolution TEM (HRTEM) imaging is used, the critical pore structures, lattice planes, and atomic arrangements within the solid can be observed [132]. In HRTEM analysis, the crystallographic information is directly related to its position in the image: the crystal structure is "imaged". This allows the direct characterization of local features like surface facets or interface identification.

However the electron beam of HRTEM may damage the microstructure of zeolites and MOFs [133]. Depending on the accelerating voltage, different electron damage mechanisms become important. In general, electron beam damage occurs more rapidly in zeolites having a higher water concentration [134] and decreased silica to alumina ratio. As another example, the sintering of small Pt particles supported on zeolite during a TEM study was also reported [135]. The scanning mode of TEM (STEM) can reduce electron beam damage produced by the continuous static illumination in HRTEM imaging [136]. Moreover, STEM images are particularly sensitive to a variation of the average atomic number and give rise to an exceptionally high signal-to-noise ratio, which is very suitable for observing metal particles in zeolites and MOFs [137]. Few TEM/STEM studies of MOFs are available in the literature. The direct imaging of intact MOF crystals by TEM was first reported for MIL-101(Cr) [138]. Díaz-García et al. [139] also 
studied nanosized MOF-74 materials in STEM mode. The image quality was sufficient to resolve the channel structure of the crystals, although the sensitivity of the MOF to the electron beam made it difficult to achieve more information on the intact materials.

\section{Concluding remarks}

Both zeolites and metal-organic frameworks are well-defined porous materials with varying structures and morphology depending on their building units. As they present very similar characteristics, the synthetic methods employed are usually similar, the hydro/solvothermal method being the one most reported. Variations of the preparation methods are guided by application requirements: smaller crystal can be obtained by ultrasound and microwave assisted methods but sometimes in detriment to the crystallinity. No matter what the synthesis procedure, a basic characterization of the structure, porosity and morphology is required to guide the posterior change of synthetic parameters or additional treatments, or to assess the suitability of the materials for the intended use.

\section{References}

[1] Férey, G. Chem. Soc. Rev. 2008, 37, 191.

[2] Olmos, A., Louis, B., Pale, P. Chem. Eur. J. 2012, 18, 4894.

[3] Bernardon, C., Louis, B., Beneteau, V., Pale, P. ChemPlusChem. 2013, 78, 1134.

[4] Chassaing, S., Beneteau, V., Louis, B., Pale, P. Curr. Org. Chem. 2016, 20, 1.

[5] Losch, P., Kolb, J.F., Astafan, A., Daou, T.J., Pinard, L., Pale, P., Louis, B. Green. Chem. 2016, 18, 4714 .

[6] Karmakar, A., Desai, A.V., Ghosh, S.K., Coord. Chem. Rev. 2016, 307, 313.

[7] Wang, L., Han, Y., Feng, X., Zhou, J., Qi, P., Wang, B. Coord. Chem. Rev. 2016, 307, 361.

[8] Corma, A., García, H., Llabrés i Xamena, F.X., Chem. Rev. 2010, 110, 4606.

[9] Liu, J., Chen, L., Cui, H., Zhang, J., Zhang, L., Su, C.Y. Chem. Soc. Rev. 2014, 43, 6011.

[10] Butova, V.V., Soldatov, M.A., Guda, A.A., Lomachenko, K.A, Lamberti, C. Russian Chem. Rev. 2016, 85, 280 .

[11] Milton, R.M. in Zeolite Synthesis, ACS Symposium Series 398, 1, Am. Chem. Soc., 1989.

[12] Loewenstein, W. Am. Miner. 1954, 39, 92.

[13] Morris, R.J. Mater. Chem. 2005, 15, 931.

[14] Barrer, R.M. Pure Appl. Chem. 1979, 51, 1091.

[15] Hölderich, W.F., van. Bekkum, H. Stud. Surf. Sci. Catal. 1991, 58, 631.

[16] Grand, J., Awala, H., Mintova, S. Cryst. Eng. Comm. 2016, 18, 650.

[17] Dyer, A. Introduction to Zeolite Molecular Sieves, John Wiley \& Sons, 1988.

[18] Harvey, G., Dent Glasser, L.S. in Zeolite synthesis, ACS Symposium Series 398, 49, Am. Chem. Soc., 1989 . 
[19] Burkett, S.L., Davis, M.E. Chem. Mater. 1995, 7, 920.

[20] Davis, M.E. Stud. Surf. Sci. Catal. 1995, 97, 35.

[21] Choi, M., Cho, H.S., Srivastava, R., Venkatesan, C., Choi, D.H., Ryoo, R. Nat. Mater. 2006, 5, 718.

[22] Valtchev, V., Smaihi, M., Faust, A.C., Vidal, L. Angew. Chem. Int. Ed. 2003, 42, 2782.

[23] Ocampo, F., Cunha, J.A., de Lima Santos, M.R., Tessonnier, J.P., Pereira, M.M., Louis, B. Appl. Catal., A 2010, 390, 102.

[24] Kirschhock, C.E.A., Feijen, E.J.P., Jacobs, P.A., Martens J.A. in Handbook of Heterogeneous Catalysis, Vol 1, 16o, Ertl, G., Knozinger, H., Schüth, F., Weitkamp, J. (Eds.), 2008.

[25] Maldonado, M., Oleksiak, M.D., Chinta, S.J., Rimer, J.D. J. Am. Chem. Soc. 2013, 135, 2641.

[26] Kessler, H., Patarin, J., Schott-Darie, C. Stud. Surf. Sci. Catal. 1994, 85, 75.

[27] Camblor, M.A., Villaescusa, L.A., Diaz-Cabanas, M.J. Top. Catal. 1999, 9, 59.

[28] Guth, J.L., Kessler, H., Higel, J.M., Lamblin, J.M., Patarin, J., Seive, A., Chezeau, J.M., Wey, R. in Zeolite Synthesis, Am Chem Soc. Symposium Series 398, Washington DC (1989) 176-195.

[29] Guth, J.L., Delmotte, L., Soulard, M., Brunard, N., Joly, J.F., Espinat, D. Zeolites 1992, 12, 929.

[30] Louis, B., Kiwi-Minsker, L. Microp. Mesop. Mater. 2004, 74, 171.

[31] Arichi, J., Louis, B., Cryst. Growth Des. 2008, 8, 3999.

[32] Losch, P., Pinar, A.B., Willinger, M.G., Soukup, K., Chavan, S., Vincent, B., Pale, P., Louis, B. J. Catal. 2017, 345, 11.

[33] Sefcik, J., McCormick, A.V. Chem. Eng. Sci. 1999, 54, 3513.

[34] Oleksiak, M.D., Rimer, J.D. Rev. Chem. Eng. 2013, 30, 1.

[35] Navrotsky, A., Trofymluk, O., Levchenko, A.A. Chem. Rev. 2009, 109, 3885.

[36] Barrer, R.M. in: Zeolite Synthesis, ACS Symposium Series 398, 11, Am Chem Soc., 1989.

[37] Ostwald, W. in Lehrbuch der Allgemeinen Chemie, vol 2, 444, Engelmann, 1896.

[38] Qin, Z., Melinte, G., Gilson, J.P., Jaber, M., Bozhilov, K., Boullay, P., Mintova, S., Ersen, O., Valtchev, V. Angew. Chem. Int. Ed. 2016, 55, 1.

[39] Larlus, O., Valtchev, V. Chem. Mater. 2004, 16, 3381.

[40] Schüth, F. Solid State Mater. Sci. 2001, 5, 389.

[41] Kirschhock, C.E.A., Kremer, S.P.B., Grobet, P.J., Jacobs, P.A., Martens, J.A. J. Phys. Chem. B 2002, 106, 4897 .

[42] Kirschhock, C.E.A., Ravishankar, R., Jacobs, P.A., Martens, J.A.J. Phys. Chem. B 1999, 103, 11021.

[43] Taulelle, F., Haouas, M., Gerardin, C., Estournes, C., Loiseau, T., Ferey, G. Colloids Surf. A 1999, 158, 299.

[44] Pope, C.G. Microp. Mesop. Mater. 1998, 21, 333.

[45] Cundy, C.S., Cox, P.A. Microp. Mesop. Mater. 2005, 82, 1.

[46] Mintova, S., Jaber, V., Valtchev, V. Chem. Soc. Rev. 2015, 44, 7207.

[47] Kosanovic, C., Bosnar, S., Subotic, B., Svetlicic, V., Misic, T., Drazic, G., Havancsak, K. Microp. Mesop. Mater. 2008, 110, 177 .

[48] Kosanovic, C., Havancsak, K., Subotic, B., Svetlicic, V., Misic Radic T., Cziraki, A., Huhn, G., Buljan, I., Smrecki, V. Microp. Mesop. Mater. 2011, 142, 139.

[49] Kosanovic, C., Havenscak, K., Subotic, B., Svetlicic, V., Misic, T., Cziraki, A., Huhn, G. Microp. Mesop. Mater. 2009, 123, 15 o.

[50] Ren, N., Subotic, B., Bronic, J., Tang, Y., Dutour Sikiric, M., Misic Radic, M., Svetlicic, V., Bosnar, S., Antonic Jelic, T. Chem. Mater. 2012, 24, 1726.

[51] Ren, N., Bosnar, S., Bronic, J., Dutour Sikiric, M., Misic, T., Svetlicic, V., Mao, J.J., Antonic Jelic, T., Hadjiza, M., Subotic, B. Langmuir 2014, 30, 8570.

[52] Davis, T.M., Drews, T.O., Ramanan, H., He, C., Dong, J., Schnablegger, H., Katsoulakis, M.A., Kokkoli, E., Mccormick, A.V., Penn, R.L., Tsapatsis, M. Nat. Mater. 2006, 5, 400.

[53] Deria, P., Mondloch, J.E., Karagiaridi, O., Bury, W., Hupp, J.T., Farha, O.K. Chem. Soc. Rev. 2014, 43, 5896 . 
[54] Schnobrich, J.K., Koh, K., Sura, K.N., Matzger, A.J. Langmuir 2010, 26, 5808.

[55] Chen, B., Eddaoudi, M., Hyde, S.T., O'Keeffe, M., Yaghi, O.M. Science 2001, 291, 1021.

[56] Ma, B.Q., Mulfort, K.L., Hupp, J.T. Inorg. Chem. 2005, 44, 4912.

[57] Zhu, Y.J., Chen, F. Chem. Rev. 2014, 114, 6462.

[58] Hayes, B.L. Microwave Synthesis: Chemistry at the Speed of Light, CEM Publish., 2002.

[59] Zou, F., Yu, F., Li, R., Li, W. ChemPhysChem. 2013, 14, 2825.

[6o] Schlesinger, M., Schulze, S., Hietschold, M., Mehring, M. Microp. Mesop. Mater. 2010, 132, 121.

[61] Pichon, A., Lazuen-Garay, A., James, S.L. Cryst. Eng. Comm. 2006, 8, 211.

[62] Armstrong, M.R., Senthilnathan, S., Balzer, C.J., Shan, B., Chen, L., Mua, B. Ultrason. Sonochem. 2017, 34, 365 .

[63] Azhdari Tehrania, A., Safarifarda, V., Morsalia, A., Bruno, G., Amiri Rudbari, H. Inorg. Chem. Comm. 2015, 59, 41.

[64] Giménez-Marqués, M., Hidalgo, T., Serre, C., Horcajada, P. Coord. Chem. Rev. 2016, 307, 342.

[65] Braga, D., Giaffreda, S.L., Grepioni, F., Pettersen, A., Maini, L., Curzi, M., Polito, M., Dalton Trans. 2006, 1249.

[66] Klimakow, M., Klobes, P., Rademann, K., Emmerling, F. Microp. Mesop. Mater. 2012, 154, 113.

[67] Klimakow, M., Klobes, P., Thunemann, A.F., Rademann, K., Emmerling, F. Chem. Mater. 2010, 22, 5216 .

[68] Capek, I. Adv. Colloid Interf. Sci. 2004, 110, 49.

[69] Rieter, W.J., Taylor, K.M.L., An, H., Lin, W., Lin, W.J. Am. Chem. Soc. 2006, 128, 9024.

[70] Liu, Q., Jin, L.N., Sun, W.Y. Chem. Commun. 2012, 48, 8814.

[71] Liu, Y., Zhang, Y., Chen, J., Pang, H. Nanoscale 2014, 6, 10989.

[72] Jiang, L.L., Zeng, X., Li, M., Wang, M.Q., Su, T.Y., Tian, X.C., Tang, J. RSC Adv. 2017, 7, 9316.

[73] Albo, J., Vallejo, D., Beobide, G., Castillo, O., Castaño, P., Irabien, A. ChemSusChem 2017, 10, 1100.

[74] Qiu, S., Zhu, G. Coordin. Chem. Rev. 2009, 253, 2891.

[75] Kittel, C. Introduction to Solid State Physics, 5th edition, John Wiley \& Sons, 1976.

[76] Cullity, B.D. Elements of X-ray Diffraction, 2nd edition, Addison Wesley, 1978.

[77] West, A.R. Solid State Chemistry and its Applications, John Wiley \& Sons, 1984.

[78] Rohrer, G.S. Structure and Bonding in Crystalline Materials, Cambridge University Press, 2001.

[79] Baur, W.H., Fischer, R.X., Shannon, R.D. Relations and Correlations in Zeolite RHO and Computer Simulations of its Crystal Structure. In Innovation in Zeolite Material Science, Grobet, P.J. et al. (Eds.), Elsevier, 1988.

[8o] Furukawa, H., Cordova, K., O'Keeffe, M., Yaghi, O. Science 2013, 341, 974.

[81] Mason, J.A., Veenstra, M., Long, J.R. Chem. Sci. 2014, 5, 32.

[82] Phan, A., Czaja, A.U., Gándara, F., Knobler, C.B., Yaghi, O.M. Inorg. Chem. 2011, 50, 7388.

[83] McCusker, L.B. Acta Cryst. A 1991, 47, 297.

[84] Baerlocher, C., McCusker, L.B. in Advanced Zeolite Science and Applications. Stud. Surf. Sci. Catal. Vol 85, Elsevier, 1994.

[85] Baerlocher, C., Meier, W.M., Olson, D.H. Atlas of Zeolite Framework Types. 5th Edition, Elsevier, 2001.

[86] Treacy, M.M.J., Higgins, J.B. Collection of Simulated XRD Powder Patterns for Zeolites (5th Edition), Elsevier, 2001.

[87] http://www.iza-online.org/

[88] Chester, W.A., Derouane, E.G. Zeolite Characterization and Catalysis: A Tutorial, Springer, 2009.

[89] Hafizovic, J., Bjorgen, M., Olsbye, U., Dietzel, P.D.C., Bordiga, S., Prestipino, C., Lamberti, C., Lillerud, K.P. J. Am. Chem. Soc. 2007, 129, 3612. 
[9o] Platero-Prats, A.E., de la Peña-O'Shea, V.A., Proserpio, D.M., Snejko, N., Gutiérrez-Puebla, E., Monge, A.J. Am. Chem. Soc. 2012, 134, 4762.

[91] Abednatanzi, S., Abbasi, A., Masteri-Farahani, M.J. Mol. Catal. A Chem. 2015, 399, 2015.

[92] Tranchemontagne, D.J., Hunt, J.R., Yaghi, O.M. Tetrahedron 2008, 64, 8553.

[93] Kraus, W., Nolze, G. J. Appl. Crystallogr. 1996, 29, 301.

[94] Herrmann, M., Kempa, P.B., Fietzek, H., Altenburg, T., Polyzoidis, A., Piscopo, C.G., Lobbecke, S. Chem. Ing. Tech. 2016, 88, 967.

[95] Young, R.A. (Ed.) The Rietveld Method, Oxford University Press, 1993.

[96] Botas, J.A., Calleja, G., Sánchez-Sánchez, M., Orcajo, M.G. Int. J. Hydrogen Energy 2011, 36, 10834.

[97] Raoof, J.B., Hosseini, S.R., Ojani, R., Mandegarzad, S. Energy 2015, 90, 1075.

[98] Gregg, S.J., Sing, K.S.W. Adsorption, Surface Area and Porosity, Academic Press, 1982.

[99] Seifert, J., Emig, G. Chem. Ing. Tech. 1987, 59, 475.

[100] Groen, J.C., Peter, L.A.A., Pérez-Ramírez, J. Microp. Mesop. Mater. 2003, 6o, 1.

[101] Storck, S., Bretinger, H., Maier, W.F. Appl. Catal., A 1998, 174, 137.

[102] Tsao, C.S., Yu, M.S., Chung, T.Y., Wu, H.C., Wang, C.Y., Chang, K.S., Chen, H.L. J. Am. Chem. Soc. $2007,129,15997$.

[103] Webb, S.W., Cconner, W.C. Sorption of Gases on Microporous Solids: Pore Size Characterization by Gas Sorption. In Characterization of Porous Solids II, F. Rodriguez-Reinoso et al. (Eds.), Elsevier, 1991.

[104] Reichert. H. Sorption of argon and nitrogen on network types of zeolites and aluminophosphates. In Characterization of Porous Solids II, F. Rodriguez-Reinoso et al. (Eds.), Elsevier, 1991.

[105] Leofanti, G., Padovan, M., Tozzola, G., Venturelli, B. Catal. Today 1998, 41, 207.

[106] Kaneko, K.J. Membr. Science 1994, 96, 59.

[107] Ravikovitch, P.I., Vishnyakov, A., Russo, R., Neimark, A.V. Langmuir 2000, 16, 2311.

[108] Leach, A.R. Molecular Modelling: Principles and Applications, 2nd Ed., Prentice Hall, 2001.

[109] Walton, K.S., Snurr, R.Q.J.J. Am. Chem. Soc. 2007, 129, 8552.

[110] Sang Bae, Y., Dubbeldam, D., Nelson, A., Walton, K.S., Hupp, J.T., Snurr, R.Q. Chem. Mater. 2009, 21, 4768.

[111] Sing, K.S.W. Chem. Ind. 1968, 1520.

[112] Barrett, E.P., Joyner, L.G., Halenda, P.P.J. Amer. Chem. Soc. 1951, 61, 373.

[113] Lynch, J., Raatz, F., Dufresne, P. Zeolites 1987, 7, 333.

[114] Ogura, M., Shinomiya, S.Y., Tateno, J., Nara, Y., Nomura, M., Kikuchi, E., Matsukata, M. Appl. Catal., A 2001, 219, 33

[115] Pérez-Ramírez, J., Mitchell, S., Verboekend, D., Milina, M., Michels, N.L., Krumeich, F., Marti, N., Erdmann, M. ChemCatChem 2011, 3, 1731.

[116] Pérez-Ramírez, J., Verboekend, D., Bonilla, A., Abelló, S. Adv. Func. Mater. 2009, 19, 3972.

[117] Lillerud, K.P., Olsbye, U., Tilset, M. Top. Catal. 2010, 53, 859.

[118] Furukawa, H., Ko, N., Go, Y.B., Aratani, N., Choi, S.B., Choi, E., Yazaydin, A.O., Snurr, R.Q., O'Keeffe, M., Kim, J., Yaghi, O.M. Science 2010, 329, 424.

[119] Farha, O.K., Eryazici, I., Jeong, N.C., Hauser, B.G., Wilmer, C.E., Sarjeant, A.A., Snurr, R.Q., Nguyen, S.T., Yazaydın, A.O., Hupp, J.T.J. Am. Chem. Soc. 2012, 134, 9860.

[120] Kaye, S.S., Dailly, A., Yaghi, O.M., Long, J.R.J.J. Am. Chem. Soc. 2007, 129, 14176.

[121] Chan, I.Y., Labun, P.A., Pan, M., Zones, S.I. Microp. Mesop. Mater. 1995, 3, 409.

[122] Meriaudeau, P., Tuan, V.A., Nghiem, V.T., Lai, S.Y., Hung, L.N., Naccache, C.J. Catal. 1997, 169, 55.

[123] Sakamoto, Y., Kaneda, M., Terasaki, O., Zhao, D.Y., Kim, J.M., Stucky, G., Shin, H.J., Ryoo, R. Nature 2000, 408, 449.

[124] Terasaki, O.J. Electron Microsc. 1994, 43, 337.

[125] Liangkui, Z., Daliang Z., Ming, X., Huan, L., Shilun, Q. Cryst. Eng. Comm. 2013, 15, 9356. 
[126] Ardenne, M., Beischer, D. Angew. Chem. Int. Ed. 1940, 53, 103.

[127] Turkevich, J.J. Chem. Phys. 1945, 13, 235.

[128] Choi-Feng, C., Hall, J.B., Huggins, B.J., Beyerlein, R.A.J. Catal. 1993, 140, 395.

[129] Koster, A.J., Ziese, U., Verklij, A.J., Janssen, A.H., de Jong, K.P.J. Phys. Chem. B 2000, 104, 9368.

[130] Janssen, A.H., Yang, C.M., Wang, Y., Schuth, F., Koster, A.J., de Jong, K.P.J. Phys. Chem. B 2003, $107,10552$.

[131] Cowley, J.M. (Ed.) Electron Diffraction Techniques vol. I and II, Oxford University Press, 1992.

[132] Terasaki, O.J. Solid. State Chem. 1993, 106, 190.

[133] Hren, J.J., Goldstein, J.J., Joy, D.C. Introduction to Analytical Electron Microscopy, Plenum, 1979 .

[134] Bursill, L.A., Lodge, E.A., Thomas, J.M.J. Phys. Chem. 1980, 286, 111.

[135] Jentoft, R.E., Tsapatsis, M., Davis, M.E., Gates, B.C.J. Catal. 1998, 179, 565 .

[136] Williams, D.B., Carter, C.B. Transmission Electron Microscopy - A Textbook for Materials Science, Plenum, 1996.

[137] Borisevich, A.Y., Wang, S., Rashkeev, S.N., Pantelides, S.T., Sohlberg, K., Pennycook, S.J. Microsc. Microanal. Proc. 2004, 10, 460.

[138] Lebedev, O.I., Millange, F., Serre, C., Tendeloo, V., Férey, G. Chem. Mat. 2005, 17, 6525.

[139] Díaz-García, M., Mayoral, A., Díaz, I., Sánchez-Sánchez, M. Cryst. Growth. Des. 2014, 14, 2479. 